\title{
A STUDY ON THE NUMEROUS ELEMENTS OF EMOTIONAL INTELLIGENCE AND LEADERSHIP QUALITIES AND ITS IMPACT ON CONFLICT MANAGEMENT: A REVIEW OF LITERATURE
}

\author{
Swati John \\ Research Scholar, Amity University Uttar Pradesh, India \\ Dr. Shyamalendu Niyogi \\ Director and Professor, AIBS, Amity University Uttar Pradesh, India
}

\begin{abstract}
The purpose of emotional intelligence is felt necessary because it is an unseen attribute of each and every person which needs to be identified and evaluated as per the needs of certain task, activity and event, where one is involved. The proposed research project aims at exploring the concept of emotional intelligence and its impacts on leadership and teamwork effectiveness. Like other competitive skills and personality aspects the notion of EI has attracted enormous popularity at academic and organizational levels. Academic institutions endeavour to develop emotionally intelligent students in order to prepare them for working effectively in their work environment. On the other hand different organizations are more inclined towards recruiting EI employees as trainers, and making investments in hiring EI professional staff and providing training to their existing workforce in order to achieve competitive edge in today's competitive work environment. Despite gaining such an enormous popularity the subject of EI remained controversial and debates exist among different scholars and researchers on different aspects of EI.The paper is focusing on the impact of emotional intelligence and knowledge management on leadership qualities. For this purpose two researchers have conducted a comprehensive study of the existing literature on the subject matter that covers; an analysis of the existing models of EI; review of debates and controversies that exist among the scholars on the subject; and different strategies through which EI can be developed on academic and organizational context.
\end{abstract}

Key words:_Conflict management, Emotional intelligence, Leadership, Organizational contexts, Organizational culture

Cite this Article: Swati John and Dr. Shyamalendu Niyogi, a Study on the Numerous Elements of Emotional Intelligence and Leadership Qualities and Its Impact on Conflict Management: A Review of Literature, Journal of Management, 6 (2), 2019, pp. 111 120.

http://www.iaeme.com/JOM/issues.asp?JType=JOM\&VType=6\&IType=2 


\section{OBJECTIVES}

There are two objectives of the research paper. They are -

- To find the relationship between emotional intelligence and Leadership at implementation level

- To find the elements of emotional intelligence and leadership qualities in different organizations

- To find the impact of emotional intelligence and leadership qualities on conflict management

\section{INTRODUCTION}

The concept of Emotional Intelligence (EI) has gained significant consideration from academia, different organizations and mainstream society. Emotional intelligence bears an important impact on self-development of the manager and his leadership qualities. Since its inception different scholars such as Daniel Goleman, Peter Salovey, John Mayer, and Reuven Bar-On have conducted comprehensive research on the subject of Emotional Intelligence. In their research work they have approached the concept of EI with different construct, conceptualized different models of Emotional Intelligence, with different corresponding measurement tools and have proposed various strategies for developing EI. Such scholarly work has made major contribution in the development of EI but it has also given rise to a number of controversial aspects over which debates exist among different scholars and researchers. Therefore by looking at the existing controversies on EI among the different scholars, thorough research is required in order to a bridge the gap and provide a single platform for achieving theoretical harmony in EI and to effectively analyze the impacts of EI at workplace on leadership and teamwork level. The main purpose of the done research project is to conduct an in-depth study of the concept of EI in order toanalyze its effectiveness on leadership and teamwork level. For example, leaders who are unable to discern and self-assess their emotions may not recognize certain cues from their co-workers or subordinates. For instance, when they feel anxious, they may avoid giving an important speech, or when they feel angry, they may inappropriately lash out at a co-worker. According to Daniel Goleman EI is a form of intelligence relating to the emotional side of life. It is the ability to recognize and manage the emotions of one's self and others, to motivate oneself and restrain impulses, and to handle interpersonal and intrapersonal relationships effectively (Goleman, 1998, p.63). In the current project the researchers conducted an extensive study of the existing literature on EI, and have focused on three main models of EI i.e. Mayer \& Salovey Model of EI, BarOn Model of EI, and Goleman Model of EI. The researchers have made an analysis of these three models in order to investigate to what extent they differ from each other. It is evident from the literature review that these models are complementary rather than contradictory to each other, but still debate exists on certain controversial aspects of EI i.e. various definitions and constructs of EI by different scholars, difference in measurement of EI, existence of contradictory views on developing EI etc.

According to Ciarrochi it helps the person to perform job as per culture and tradition of that region (Ciarrochi, J, V, et al, 2000, p. 539). For instance if a student is emotionally intelligent his progress and result during the academic life would be much more appreciative as compared to that of another student who is not emotionally intelligent. According to Bar-On it develops the personality mix qualities of the individual in efficient manners (Bar-On, 2004, p.228). Similar it is the case with those employees who work on the front-end deal directly with the customers. If the employee is motivated and emotionally intelligent then he would be in a better way equipped to deal with the customer in a satisfying and delighting way, due to development and improvement of intrapersonal and interpersonal skills (Goleman, 1998, p.63). But 
A Study on the Numerous Elements of Emotional Intelligence and Leadership Qualities and Its Impact on Conflict Management: A Review of Literature

emotional intelligence cannot be limited to only those employees who deal with customers. Other employees equally need emotional intelligence in their daily routine life in terms of their interaction with their supervisors, upper management, subordinates, colleagues etc because EI develops good job behavior of individuals in the organization (Carmeli, 2003).

Conflict Management is also very important part of social competences in emotional intelligence because in it negotiation and resolving disagreements are discussed and negotiators with emotional competence are much more likely to reach win-win agreement. Inspiration leadership is very concerning here because in it the value of the guiding to the team is very important and admirable. Conflict management has great importance in the field of decision making because the decisions are accepted and rejected on the basis of the betterment of its implementation, therefore the wise decisions are made for the organizations to improve its progress for more profit and goodwill in the current market. Change catalysts are those who develop changes for the betterment of the organization and always try to give more suitable environment and make the process very smooth for the best outcomes. In the end of the social awareness the teamwork and collaboration is very important to discuss because creating group synergy in pursuing collective goals. Collaboration gives best solutions of the problem in the organizations. Networking is also the part of the collaboration that gives more interaction with other societies. Collaboration and networking gives the better opportunities to avail the chance of hire highly skilled persons through reference and also gives innovative ideas from the common society. Like in the world of science; teams are also becoming more pervasive in business organizations. Team synergies can lead to performance that far exceeds the aggregated sum of what individual members can accomplish on their own.

\section{LITERATURE REVIEW}

Arrangements should be as such that students at the very educational level should be made emotionally intelligent so that they can later utilize the same skills during their careers. For instance if a manager is emotionally intelligent then he would be making much sound decisions as compared to a manager who isn't literate about all this (Dimitriades, 2007; Barling et al., 2000; Bass, 2002; Caruso et al., 2002; Higgs and Aitken, 2003; Kerr et al., 2006; Palmer et al., 2001; and Rosete and Ciarrochi, 2005), personals with EI can perform their job in the best manners than others (Abraham, 2000; Carmeli, 2003). Development of EI in the employees gives them more job satisfaction (Carmeli, 2003). Many ALS oriented casestudies reveal a significant change in the levels of samples' emotional intelligence when measured both before and after the ALS driven course. This shows that emotional intelligence is not something, which cannot be controlled or managed, and it's something natural or inbound. No, emotional intelligence can be addressed with the help of ALS, and can be modified to a great level if proper arrangements are being brought in place. EI on work place gives more productivity to the organizations (Boyatzis et al., 2000) and then more productivity generates more profit for the organization (Langhorn, 2004). Johnson and Cross (2004, 55) express the view that organisations are 'healthy or not healthy to the degree that people in the system believe it is a responsive institution'. These authors assent that people tend to feel disempowered or powerless in cases where there is a lack of effective intellectual and academic leadership. They conclude that change (needs to be) a process of 'educational interaction and negotiation among interest groups' (Johnson and Cross, 2004, 55). After having evaluated salient aspects of managerial skills in national education authorities, Froneman (2003) expresses his concern about the management acumen in educational leadership. The concept of Emotional Intelligence was introduced for the first time by Peter Salovey and John Mayer (1990) and since then the subject of EI has remained the main focus among researchers, organizations, and academia. A prominent researcher Daniel Goleman came across the work of Mayer and Salovey and decided 
to conduct his own research on the subject of EI. In furtherance of this initiative Goleman conducted a very useful research and published the first book on Emotional Intelligence (Goleman, 1995; Goleman 1990, Video www.haygroup.com). After giving the concept of EI it has become very attractive in different fields of life like organizations, educational institutes and other kind of relevant department where it can show its positive effects. On the other hand the EI is still in process to understand that it is cognitive or emotional behavior measurements. (Stys \& Brown 2004, p.4). In furtherance of this clarification several researchers have attempted to accurately describe and assess the concept of EI (e.g. Salerno, 1996; Henig, 1996; Bennets, 1996; Gottman, 1997; Segal, 1997; Cooper and Sawaf, 1997; and many other books and articles). In the result of working, study and research on EI much kind of measurement tools has been made on it and among these there are many controversies to adopt the best tool as measurement of the EI on the work place. EI helps the persons on the workplace to change their behavior towards their job and given task as per the requirement.EI has been perceived distinct from traditional IQ and is deemed crucial in predicting many real-life outcomes (Ciarrochi, J, V, et al, 2000, p. 539).Goleman (1996) stated that IQ and EI have two different impressions to pursue the personality of the individuals. Goleman has given more emphasis on EI rather than on IQ. According to him IQ is less important than the EI, if individual has high IQ it not necessary that he will be successful in every field of life like mange the relationships, best on work place and win every task but the chances are most prominent if individuals has high EI it may be the cause of successful life and be the best in all fields and dealing and manage the relationships of family and friends and etc. Those individuals who know and can manage their own emotions and feelings (intrapersonal intelligence) and of others (interpersonal intelligence) are at an advantage in any domain of life. Goleman (1998) further states that even though an individual possesses high EI, does not mean that he will have learned the emotional competencies that are of vital importance at work, he will rather need to learn and develop emotional competence, which is a learned capability based on EI that leads to high performance at work and that the level of EI determines one's potentials for learning the practical skills that are based on its five elements, i.e. self-awareness, motivation, self-regulation, empathy, and adeptness in relationship.

The main focus of EI literature has been on the hypothesized value of EI to affect individual success (Higgs and Dulewicz 1999; Goleman 1998), and some empirical support has been established for a positive association between EI and work performance (Donaldson-Feilder and Bond 2004, 190). The term EI is defined by different scholars and researchers in books and scholarly articles. Different researchers have defined and constructed the notion according to their own perspective and conceptual approach. In order to define the term EI, the current research has mainly focused on the study of prominent researchers in the field of EI, such as Peter Salovey and John Mayer (Mayer \& Salovey 1993; Mayer \& Salovey, 1997; Salovey et al, 2004), Daniel Goleman (Goleman, 1995; Goleman, 1998), and Reuven Bar-On (Bar-On, 1997; BarOn, 2004). John Mayer and Peter Salovey (Mayer \& Salovey 1993; Mayer \& Salovey, 1997; Salovey et al, 2004) are considered as the originators of the notion of Emotional Intelligence (EI). In their article on Emotional Intelligence, they have defined the term EI as the subset of social intelligence that involves the individual's ability to monitor his own and others' feelings and emotions, the ability to discriminate among them and to employ this information to guide one's thoughts and actions. (Salovey\& Mayer, 1990; Mayer \& Salovey, 1993) but subsequently Salovey and Mayer came up with more simplified definition of EI which means it is an aptitude to perceive and assimilate emotion in order to facilitate thought, and understand and regulate emotions to promote personal growth (Mayer \& Salovey, 1997, p.3). Another famous researcher of the emotional intelligence construct is Reuven Bar-On (BarOn, 1997; BarOn, 2004), the originator of the term emotional quotient. He states that EI is an incorporation of non-cognitive capabilities, competencies, and skills that influence individual's ability to 
A Study on the Numerous Elements of Emotional Intelligence and Leadership Qualities and Its Impact on Conflict Management: A Review of Literature

succeed in coping with environmental demands and pressures. He has adopted slightly different point of view regarding the notions of EI, according to his view point EI as being concerned with understanding oneself and others, relating to people, and adapting to and coping with the immediate surroundings to be more successful in dealing with environmental demands (BarOn, 1997, p.95). He described Emotional Intelligence (EI) as an eclectic mix of traits, i.e. happiness, self-esteem, optimism, and self-management, rather than as ability based (Bar-On, 2004, p.228). According to Bar-On it develops the personality mix qualities of the individual in efficient manners to perform the task in good manners (Bar-On, 2004, p.228), when individual become able to evaluate the EI level in his personality then he can perform the duty in well manners than others because he not only work with brain but also work with the heart of the requirement of job. On the other hand a prominent researcher and psychologist Daniel Goleman (Goleman, 1995; Goleman, 1998) defines the term Emotional Intelligence (EI) in broader sense. According to him EI is a form of intelligence relating to the emotional side of life that gives approach to understand the situation of others. It is the ability to recognize and manage the emotions of one self and others, to motivate oneself and restrain impulses, and to handle interpersonal and intrapersonal relationships skills efficient and effectively (Goleman, 1998, p.63).

Our primary measures of leadership effectiveness will be based on a structured performance management assessment. The structured performance management system assesses employees' progress towards organisational goals (Corporate Leadership Council, 2002). This system is seen as a good indicator of an individual's leadership effectiveness (Management Advisory Committee 2001; Corporate Leadership Council 2002; Hogan, Curphy\& Hogan, 1994). It establishes whether an individual meets business outcomes in such a manner that they not only achieve results but also build effective working relationships. Importantly, the performance management system is tied to concrete outcomes for the individual: Leaders who score well on the system receive larger bonus pay increases (up to $15 \%$ of their normal pay). This study sought to address two major research questions. As stated earlier, after getting inspired from the work of Salovey and Mayer in the 1990's Daniel Goleman started his own research on the subject of EI and in furtherance of this initiative he wrote a book on Emotional Intelligence (1995), this remarkable book gained tremendous popularity among the public and private sectors with the concept of EI becoming popular. The model introduced by Daniel Goleman mainly focuses on EI as an extensive range of competencies and skills that drive the performance of individuals in the workplace. Goleman's model prescribes five main constructs and each construct consists of a set of emotional competencies (see figure 1). As mentioned before, according to Goleman (1998) Emotional competencies are not inborn talents, but rather learned capabilities that can be learned and developed to achieve outstanding performance in different aspects of life, which indicates that Goleman conceives that individuals are born with a common EI that determines their strength for learning emotional competencies. In his opinion EI has great influence in working behavior, performances and interest towards tasks, and also effects on practical and technical skills of the leader and team in the institutions and organizations. EI through ALS is the best learning way for students at their study institutions to develop and understand the concept of EI as theoretical and to some extent practical approach in their student life. And then as they become the part of organization these students will behave as per required EI competencies in their practical life successfully. According to Goleman the importance of Emotional Intelligence concept on organizational and institutional level gives best learning approach about the abilities of the leadership and teamwork for excellent results. This model is focused on discussing personal competence and social competence. Personal competences contain the information and concepts about self-awareness, which is very important for organizational development. It gives the right option to understand the situation 
and then go for the more suitable alternatives. It helps to recognize the effects of emotions in the organization and its impacts on performance. Emotional self-awareness is the integral part of the first cluster of Goleman's model, as it emphasizes on individuals' emotional selfperception and then in the second competency of the first cluster i.e. managing emotions, it proposes the best available option to solve the problem that has been encountered. After access the self-awareness there is need to access the accurate self-assessment that helps to gives the accurate results for the individuals and their task in the organization because in it individuals can recognize the strengths and weaknesses of the employees and choose the right person for right location in the organization as per the requirement of the task. Accurate self-assessment gives the confidence to do for more work and complete the task because it give the results to measure the worth and capabilities of the individuals and the personals that are related to the organization and task. After that there is need to measure the self-management that is very important for the responsible personals of the department and for those who are the in charge of the given task because they have to report to the concern authorities about their job, task, work, progress, control and responsibilities. Selfmanagement gives a lot of helps to the managers to access their self for better understanding of their behavior and control on their emotions in the organization towards their tasks and given goals. Emotional self-control is very much concerning here after self-management because it helps to keeping disruptive emotions and impulses in check.

There are different tools that are used by researchers and scholars in order to measure the level of EI with reference to leadership and teamwork. These tools help for further research on the topic of EI in organization or where its need is being felt. This technique of measurement the EI in different fields of working environment gives appropriate results about the level of emotions in the individuals. Further after evaluating the level of EI in the individuals on work place, the need of EI is required to develop and then maintain in the staff for better output or successful completion of task. Therefore the organizations or institutes where people work with the concept of EI they are working better than others and give more productive progress and improving their achievement in innovation works. Due to the improvement of EI the level of collaboration and interaction does enhance in the organizations efficiently and effectively. Mayer and Salovey Model of EI (Mayer et al, 2003) is measured by using Mayer, Salovey, and Caruso Emotional Intelligence Test (MSCEIT). This measurement tool requires the respondents to perform a number of tasks relating to EI. The respondents have to work on the given task by keeping the manners of developing EI in their mind and work flow activities, then after they are evaluated by the results taken from their progress through given task. BarOn's model (BarOn, 2004) and Goleman's (Goleman et al, 2002) model use self-report measures of EI. This measurement tool is seems to be prominent to measure the level of EI on work place in the given task, and then its further development and maintenance on work place and improvement / awareness for upcoming situations. Bar-On model is measured by using Emotional Quotient Inventory (EQ-I) while Goleman's model is assessed through Emotional Competency Inventory (ECI). These measurement tools are very help full for both researchers and key personals of the organization to evaluate the level of EI and then its implantation for more work/output. (See figure 3 for different EI models and corresponding measures). Leadership development programs sometimes fail because the organizational practitioner carried out emerging concepts as a quick-fix to organizational issues, without having a complete understanding of the leadership concept (Ready \& Conger). In the early 21 st century, no clear universally agreed-upon model for leadership development exists (Gentry \& Leslie, 2007). Organizational development practitioners continue to develop new programs to address emerging organizational concepts such as self-management, social-network development, flat structures, and information management (Cook, 2006; Gentry \& Leslie, 2007; Raelin, 2004). The lack of alignment between leadership development and the new organizational realities 
A Study on the Numerous Elements of Emotional Intelligence and Leadership Qualities and Its Impact on Conflict Management: A Review of Literature

may be a primary reason for subsequent leadership ineffectiveness (Raelin; Ready \& Conger, 2003). The construct of leadership continues to change (Hernez-Broome \& Hughes, 2004). One relatively new leadership concept that has emerged is emotional intelligence (Kunnanatt, 2004). Emotional intelligence, which is the ability to use emotions to help reason (Mayer, 2007), has been closely tied with elements of leadership effectiveness through the empirical research of several recent studies (Van Dijk \& Freedman, 2007). The concurrent events-emergence of new leadership development criteria due to the new organizational paradigm and emergence of emotional intelligence as part of the leadership construct - have resulted in opportunities for further research studies.

Different researchers have used the Mayer and Salovey (1997) model in developing their own models and corresponding measurement tools of EI. Jordan et al. (2002, p.198), for instance, established an instrument of measuring workgroup emotional intelligence which is purely based upon a previous model of EI established by Salovey and Mayer (1990). By indepth study of the WEIP it seems different than other measurement tools because firstly it is not a general EI measure and only purports to assess the level of workgroup's EI, secondly all the aspects refer to members of the participant's team, and finally it measures EI within a single perspective operating in a workgroup. The WEIP has gone through successive amendments and modifications since its establishment by Jordan et al. (2002, p.201). WEIP is divided into two scales i.e. ability to deal with own emotions (intrapersonal) and ability to deal with others' emotions (interpersonal) and then further divided into sub-scales, the main components of this model are perception of emotions that is related to the awareness of own emotions, ability to recognize others emotions, ability to detect false displays of emotion. Second component is management of emotions that related to ability to discuss own emotions, ability to manage other emotions, this ability gives and make the thinking style broad about others and then person become able to understand the term empathy. Third component is understands of emotions that related to ability to discuss own emotions, ability to detect false displays of emotions and empathetic concern. The fourth component is ability to generate which is related to ability to discuss own emotions, ability to manage other emotions. And then after we find two scales and their final results is shown as workgroup emotional intelligence, which is the result of this model about EI. Traditional top-down control and organizational hierarchy have been replaced by a more dynamic and flattened structure that relies on fluid networks and teams, and employees have a much greater degree of involvement in organizational decision-making (American Management Association/Human Resources Institute, 2005). The paradigm shift has created a problem for organizational managers and practitioners relative to creating new and effective management and leadership development practices (Bernthal \&Wellins, 2006). Leadership is often considered an important element of the organization, resulting in an organizational priority for strong leaders (American Management Association/Human Resources Institute, 2005). As a result, leadership and management development have become areas in which companies invest major resources (Cook, 2006; Murphy \& Riggio, 2003; Raelin, 2004) and the areas have become a large volume business for organizational practitioners (Ready \& Conger, 2003). Some critics (Locke, 2005) have even stated that EI cannot be acknowledged as a form of intelligence, with particular reference to Goleman's definition and construct of the EI and that it would be more appropriate to re-label the concept as a skill rather than intelligence Some researchers also suggest that emotional intelligence can be learned and strengthened through different development programs, while other claims that it is an inborn characteristic. These contradictory theories have emerged due to the fact that it is a relatively innovative area of psychological research and the notion of EI is in its infant stage which is in the process of further growth and development, therefore the concept is either too broadly defined or constantly changing. Further research is needed on the subject of EI in order to 
determine an understandable conceptualization of EI on leadership and teamwork level. Locke (2005) claims in his criticism that the concept of EI is a misinterpretation of the intelligence construct and argues that it does not meet the requirements to be deemed as intelligence at all as he makes distinction between cognition and emotion. He argues that the concept of EI is invalid both because it is not a form of intelligence and is defined so thoroughly and inclusively that it has no understandable meaning. He differentiates the concept of EI from actual intelligence and from rationality. He further recognizes the actual relation between reason and emotion, and then reveals the main insufficiency of the concept of EI with reference to leadership. Finally, the author suggests the concept should be re-labeled and referred to as a skill. Leadership in the study was viewed from the perspective of the managersubordinate relationship, where the manager influences the subordinate to achieve tasks or projects through the use forcing and nonforcing behaviors (Emans et al., 2003). Mintzberg (2003) suggested that the organizational manager has three roles: managing action, managing information, and managing people. Mintzberg suggested that when managers are managing people, they are acting as organizational leaders. Organizational managers lead their subordinates by means of forcing and nonforcing tactics (Emans et al.). The tactics can be considered leadership behaviors and are either transformational or transactional (Emans et al.; Yukl et al., 2002). Yukl et al. described transactional categories as task and relations behavior, which also coincide with the Situational Leadership II theory, one of the more prominent theories used by organizational practitioners (Blanchard, 2007). The task and relations behaviors, which are also referred to as directive and supportive behaviors, provide the basis for defining the specific leadership behaviors in the study.

According to Roy Childs (2004) Self-assessment Questionnaire has certain limitations. For instance how an individual can assess his own EI if he is unaware of himself. He further suggests that other useful and sophisticated methods i.e. 360 Degree Feedback process and experiential exercise can be adopted in assessing and developing EI in teams and leaders. Moreover, although Goleman's research on the subject of EI has made positive contribution in the field of EI, but his work has been criticized for considering that EI is a form of intelligence. For instance Eysenck (2000) argues that Goleman's approach towards the notion of EI contains suppositions about intelligence in more general sense, and that it even contradicts to the researchers' expectations when studying different categories of intelligence.

\section{CONCLUSION}

In emotional perception the concept is that to understand the own feelings and express emotions to others and also emotional needs exactly to others. Emotional perception also helps to make skills to identify the true and false expressions of emotions. In emotional integration have the skills to make link of the job and worker as per the feelings of the individuals towards his given task. In understanding emotions there is concept of empathy is used to facilitate and make convenience the person and his given job and in the last Emotional management have skills to understand the situation and then proper usage of emotions at work place either use it or not in this situation. Emotional Intelligence (EI) gives the broad vision of thinking and decides to take step in the regard of wise ways. EI helps the person to go for the better option because this is the difference between EI concept gained person and without EI qualities in the personality. We believe that more systematic work needs to be undertaken on the area of emotional intelligence and emotional leadership within higher education institutions, especially during periods of restructuring and change. Our results seem to suggest that effective leadership cannot be accomplished by the simple adoption of a rational planning model. It seems clear that leadership comprises both intellectual and emotional intelligence facets and that both these facets need to be attended to during the training of leaders to equip them with sufficient management (and, indeed, survival) skills. This may be especially true in times of change and 
A Study on the Numerous Elements of Emotional Intelligence and Leadership Qualities and Its Impact on Conflict Management: A Review of Literature

transformation (which are often characterised by turbulence) and its regular concomitant sprout, namely the need for adjustment.

\section{REFERENCES}

[1] Allen, R., \& Pond, P, Helping business achieve their full potential [Electronic Version]. Retrieved September 7, 2005, from http://www.centerod.com/centerod_articles.html, 2003

[2] American Management Association/Human Resources Institute, Leading into the future: A global study of leadership: 2005-2015 [Electronic Version]. Retrieved October 15, 2007, from http://www.amanet.org/research/pdfs/HRILeadershipSurv05.pdf, 2005

[3] Bailey, C., \& Butcher, D, Business performance and business leader development: The catch-22 [Electronic Version]. Retrieved January 23, 2008, from http://www.som.cranfield.ac.uk/som/groups/gmdp/downloads/BusinessLeaderDe velopment.pdf, 2003

[4] Brousseau, K., Driver, M., Hourihan, G., \& Larsson, R, The seasoned executive's decisionmaking style. Harvard Business Review, 84(7/8), 2006, pp 183-184.

[5] Brown, F. W., \&Moshavi, D, Transformational leadership and emotional intelligence: a potential pathway for an increased understanding of interpersonal influence. Journal of Organizational Behavior, 26, 2005, pp 867-871.

[6] Bryant, S., E, The role of transformational and transactional leadership in creating, sharing and exploiting organizational knowledge. Journal of Leadership \& Organizational Studies, 9(4), 2003, pp 32-44.

[7] Cohen, J., Cohen, P., West, S., \& Aiken, L, Applied multiple regression/correlation analysis for the behavioral sciences (3rd ed.). Mahwah, NJ: Lawrence Erlbaum, 2003

[8] Collins, J, Level 5 leadership: The triumph of humility and fierce Resolve. Harvard Business Review, 83(7/8), 2005, pp 136-146.

[9] Cone, J., \& Foster, S, Dissertations and thesis: From start to finish (12th ed.). Washington, DC: American Psychological Association, 2004

[10] Crewsell, J. W, Educational research: Planning, conducting, and evaluating quantitative and qualitative research. Upper Saddle River, N.J.: Pearson, 2005

[11] Dasborough, M. T, A critique of emotional intelligence: What are the problems and how can they be fixed? Personnel Psychology, 60(1), 2007, pp 235-238.

[12] Daus, C. S., \&Ashkanasy, N. M, The case for the ability-based model of emotional intelligence in organizational behavior. Journal of Organizational Behavior, 26, 2005, p 453-466.

[13] Emmerling, R., \& Goleman, D, Emotional intelligence: Issues and common misunderstandings. Issues in Emotional Intelligence Retrieved August 10, 2007, from http://www.eiconsortium.org/ , 2003

[14] Ercikan, K., \& Roth, W. M, What good is polarizing research into qualitative and quantitative? Educational Researcher, 35(5), 2006, pp 14-23.

[15] Freedman, J, Emotional WHAT? [Electronic Version]. EQ Today. Retrieved September 20, 2007, from http://www.eqtoday.com/02/emotional.php, 2003

[16] Goleman, D, What makes a leader? Harvard Business Review, 82(1), 2004, pp 82-91.

[17] Goleman, D., Boyatzis, R., \& McKee, A, Primal Leadership: Learning to lead with emotional intelligence (1st ed.). Watertown, MA: Harvard Business School, 2004

[18] Grewal, D., \& Salovey, P, Feeling smart: The science of emotional intelligence. American Scientist, 93, 2005, pp 330-339. 
[19] Holt, S., \& Jones, S, Emotional intelligence and organizational performance: Implications for performance consultants and educators. Performance Improvement, 44(10), 2005, pp $15-21$.

[20] Hoopes, J, False prophets (1st ed.). Cambridge, MA.: Peruses, 2003

[21] Kent, T. W, Leadership and emotions in health care organizations. Journal of Health Organization and Management, 20(1), 2006, pp 49-66.

[22] Kornacki, S., \& Caruso, D, A theory-based, practical approach to emotional intelligence training: Ten ways to increase emotional intelligence. In J. Cairrochi\& J. Mayer (Eds.), Applying Emotional Intelligence (1st ed.). New York: Psychology Press, 2007

[23] Kotterman, J, Leadership Versus Management: What's the Difference? The Journal for Quality and Participation, 29(2), 2006, pp 13-17.

[24] Lussier, R., N, Human Relations in Organizations (6th ed.). New York: McGrawHill. Madlock, 2005

[25] Martin, M. M., Bogdan, L., \& Ervin, M, The impact of communication traits on leadermember exchange. Human Communication, 10, 2007, pp 451-464.

[26] Stringer, L, The link between the quality of the supervisor-employee relationship and the level of the employee's job satisfaction. Public Organization Review, 6, 2006, pp 125. 